\title{
O espetáculo de Philip Astley (Paris, 1786)
}

\author{
The spectacle of Philip Astley (Paris, 1786) \\ Mario Fernando Bolognesi
}

\begin{abstract}
Mario Fernando Bolognesi
Professor Visitante no Programa de Pós Graduação em Artes Cênicas da Universidade Federal da Bahia (Ufba)

Professor colaborador no Programa de Pós Graduação em Artes da

Universidade Estadual Paulista "Júlio de Mesquita Filho" (Unesp)

Pesquisador do CNPq
\end{abstract}

1 Apoio: Fundação de Amparo à Pesquisa do Estado de São Paulo (Fapesp) e Conselho Nacional de Desenvolvimento Científico e Tecnológico (CNPq).

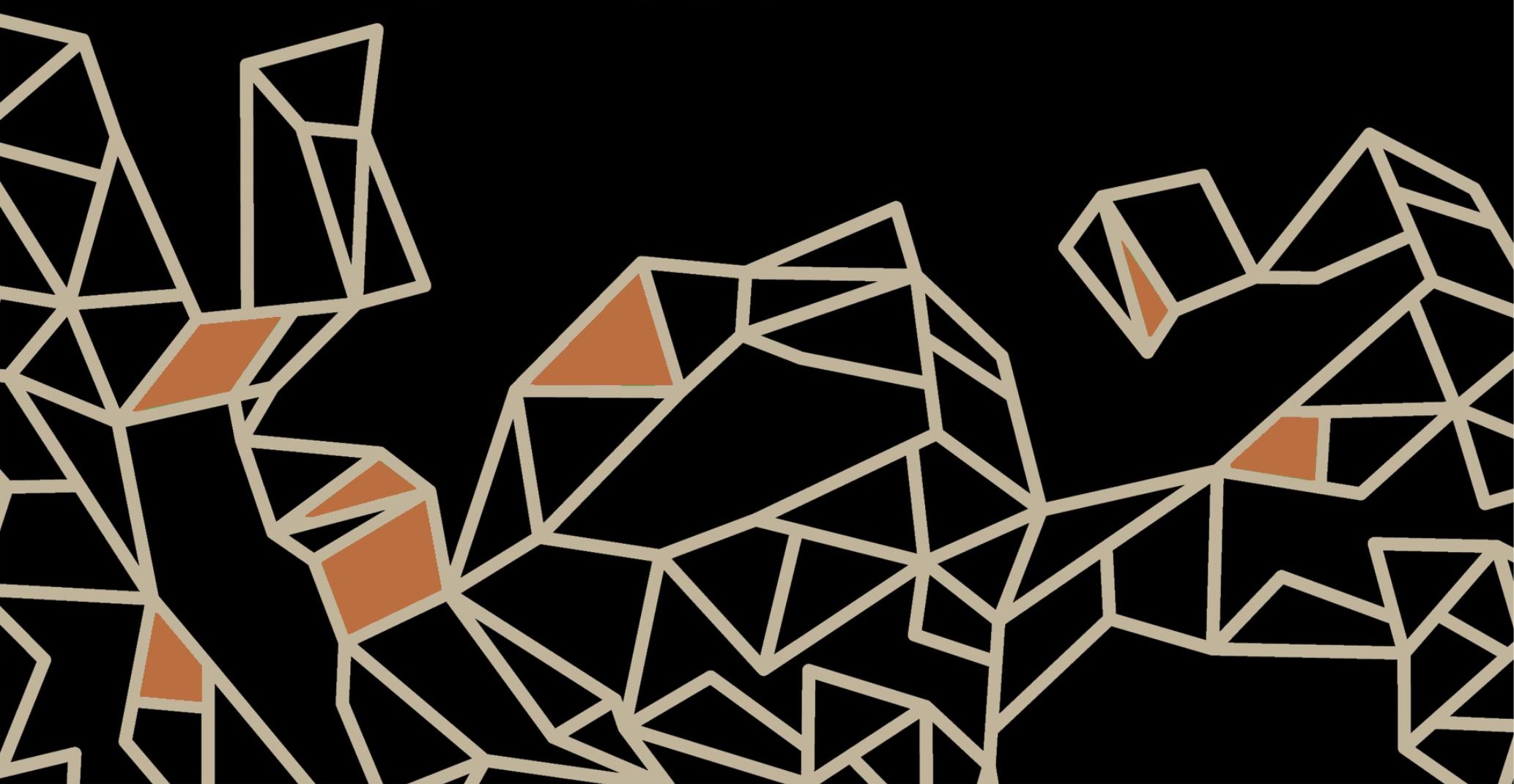




\section{Resumo}

Documento anônimo de 1887 descreve e comenta um espetáculo circense apresentado pela companhia de Philip Astley, em 1786, em Paris. Ele se baseia em escritos de Pidansat de Mairobert. O espetáculo de Astley era organizado a partir do princípio da montagem de atrações, base para os futuros espetáculos circenses.

Palavras-chave: Philip Astley, Montagem de atrações, Espetáculo circense.

\section{Abstract}

Anonymous document of 1887 describes and comments on a circus spectacle presented by Philip Astley's company in 1786, in Paris. It is based on writings of Pidansat de Mairobert. The show of Astley was organized by the principle of the montage of attractions, base for the future circus spectacles.

Keyboards: Philip Astley, Montage of attractions, Circus spectacle.

\section{O documento}

A Biblioteca Nacional da França, em seu arquivo digital Gallica (http://gallica.bnf.fr), guarda um importante documento para a compreensão dos primeiros espetáculos de circo, dirigidos por Philip Astley (1741-1814) (WARD, 2018, p. 11) e apresentados no Anfiteatro Inglês dos senhores Astley pai e filhos. Com uma tiragem de apenas 30 exemplares e 16 páginas de texto, Les anciens cirques: un soir chez Astley (25 Avril 1786) (LES ANCIENS..., 1887) foi editado em Londres por John Adamson, em 1887, porém, impresso em Paris pela Maison Quantin (informação constante da página 16). A edição não traz informações a respeito do autor da obra. Entre a data da edição, que consta na página de rosto (1887), e a referência ao espetáculo de 1786 há um hiato, portanto, de um século.

\section{O preâmbulo}

A primeira frase do texto questiona o cansaço do leitor para com o Nouveau Cirque $^{2}$ e o convida a um espetáculo de Philip Astley, de 1786. Em Paris, na rua

2 Não confundir com o "circo novo", tendência contemporânea do espetáculo circense. 
Saint-Honoré, 251, em 1886 (portanto, um ano antes da publicação do texto), foi inaugurado o Novo Circo, que encerrou suas atividades em 1926. O proprietário era Joseph Oller (1839-1932), sócio-fundador da conhecida casa de shows Moulin Rouge, em 1889. O Novo Circo tinha como diferencial uma arena aquática e o espetáculo incorporava números executados na e com a água. $\mathrm{O}$ autor, então, remete o leitor ao Anfiteatro de Astley, localizado na entrada do Faubourg du Temple, em Paris, explicando, inclusive, o caminho a percorrer a pé para alcançá-lo.

Em seguida, o texto fornece informações básicas a respeito de Philip Astley, que na época teria uma "quarentena de anos"3 informação que não foge aos dados de realidade. Astley nasceu em 1741 e, portanto, em 1786, data a que se refere o documento, contava com 45 anos. Anota, em seguida, o local de nascimento de Astley, a "pequena cidade de Staffordshire" (Newcastle-under-Lyme, cidade natal de Astley, faz parte do condado de Staffordshire). Astley, nos dizeres do documento, era metade soldado e metade cavaleiro e "havia guerreado contra nós" (p. 2) - o suboficial do exército inglês lutara contra a França durante a Guerra dos Sete Anos (1756-1763). Em 1793, as desavenças entre França e o Reino Unido se acirraram e culminaram no combate dos ingleses aos bonapartistas e Astley foi forçado a deixar Paris.

A partir de 1793, em Paris, o Anfiteatro de Astley continuou suas atividades sob a direção de Antonio Franconi (1738-1836), que se dedicava, no interior da França, a adestrar e apresentar espetáculos com animais. Em Rouen, adestrou touros para um espetáculo, modalidade rejeitada pela população. Em Lion, ele se dedicou a adestrar e exibir aves. Franconi, em 1783, dirigiu-se à capital para apresentar seus pássaros sábios, quando se associou a Astley. A associação, em 1783, foi bastante efêmera, pois "os parisienses preferiam os exercícios de cavalos aos pássaros de Franconi” (BEAULIEU, 1905, p. 102). Em 1791, Franconi retorna ao Anfiteatro como cavaleiro e adestrador de cavalos, as relações entre ambos se consolidam e ele passa à condição de diretor do Anfiteatro Astley, após a necessária fuga do cidadão inglês, Astley, e seu retorno à Inglaterra.

Retornando ao documento e antes de adentrar as descrições e observações dos números apresentados, o texto aponta que Astley ganhou notoriedade ao reunir em um mesmo espetáculo os cavalos, os acrobatas e a

3 Todas as citações são tradução nossa. 
pantomima. Informações acerca de Astley continuam a constar da escrita, com ênfase aos primeiros anos após deixar o exército inglês e se dedicar ao espetáculo de montaria e evoluções sobre o cavalo, até o ano de 1782, quando ele chegou com sua trupe a Paris e fundou o Anfiteatro. Antes, em 1774, a convite da realeza, Astley e sua companhia se apresentaram em Versailles.

Continuando com informações acerca da história pregressa do espetáculo de circo, o texto informa que em território francês outros empreendedores organizaram espetáculos equestres, tais como Hyam, conhecido como o "herói inglês", $\mathrm{e}$ Balp, o "marido da bela espanhola."Tais informações são acrescidas, em nota de rodapé, de fontes bibliográficas. Para Hyam, são citados Bachaumont (MÉMOIRES..., 1784, v. 7, p. 231) e Campardon (1887, v. 1, p. 405)4. Os espetáculos de Hyam e Balp não se aproximavam aos de Philip Astley, pois este acrescentava outras atrações. Quais eram essas atrações? Ao leitor, então, é apresentado o programa do circo, que fora comprado pelo anônimo autor do texto (ou autores?).

\section{Os exercícios}

O programa do espetáculo, reproduzido no documento nas páginas $4 \mathrm{e}$ 5 , trazia inicialmente o nome da companhia, Anfiteatro Inglês dos senhores Astley pai e filhos, seguido da ordem dos exercícios e da data da apresentação, 25 de abril de 1786, uma terça-feira. A primeira parte era composta por: (1) dança do minueto com 12 cavalos; (2) salto da fita, pela senhorita Price; (3) criança de 39 meses, fenômeno da natureza, tocando cravo; (4) Dick Turpin, cavalo livre, apresentado pelo senhor Astley pai; (5) O general Jocko, macaco na dança da corda. Segue um intervalo com apresentação da trupe de cães amestrados, sob o comando do senhor Saunders.

A segunda parte apresentava as seguintes atrações: (1) "A Beleza dominando a Inconstância", pela senhorita Saunders e o senhor Astley filho; (2) "A metamorfose do camponês", pelo senhor Price; (3) "O minueto de Devonshire," executado pelo senhor Astley filho; (4) "As lavadeiras inglesas", ou "O triunfo de Arlequim," pantomima com a participação de todos os artistas.

4 Campardon: nos referidos a volume e páginas, baseia-se em trechos das Mémoires secrets, de Bachaumont (MÉMOIRES..., 1784, v. 7, p. 231), publicadas originalmente no Almanach Forain, em 1775 (AMPARDON, 1877, v. 1, p. 405). Quanto a Balp, ver Campardon (1877, p. 80). 
O programa também informa que os referidos exercícios teriam início precisamente às quatro horas, seguidos dos valores dos ingressos e dos respectivos lugares: três libras, os primeiros lugares; 1,16 , os segundos; 1,4 , os terceiros e 0,12 , as quartas colocações. No dia seguinte, quarta-feira, a companhia folgaria, retornando às atividades na quinta, com a apresentação da pantomima "O Alfaiate Inglês" (p. 5). Nota-se nessa parte final que o programa dedica espaço à divulgação das próximas apresentações, recurso que visa expandir o público e indica o caráter profissional e comercial da atividade circense de Astley.

A singularidade da casa de espetáculo é apontada na escrita, opinião secundada por Mouffle d'Angerville (1728-1795), último dos redatores das Mémoires secrets, entre os anos de 1779 a 1784 (MÉMOIRES..., 1784, v. 23, p. 280). O texto destaca os candelabros que "iluminam admiravelmente" a pista circular, reservada às atrações circenses, o palco, destinado à representação das pantomimas e ao menino músico, e a tribuna ao alto, ocupada pela orquestra (MÉMOIRES..., 1887, v. 23, p. 6).

\section{Números e artistas}

Na sequência, o texto tece comentários a respeito das apresentações e em particular dos artistas. Por vezes, o tom da narrativa é irônico, às vezes é depreciativo, outras é elogioso. Em muitos casos, no entanto, a escrita revela o afã de uma crônica voltada à burguesia parisiense, preocupada menos em analisar o espetáculo que em pontuar dados que resvalam na moral e nos costumes de artistas e público. Assim, Philip Astley é apresentado como o homem mais belo da Europa, afirmação baseada nas Mémoires secrets (MÉMOIRES..., 1783, v 21, p. 70), apesar de estar "acima do peso" (p. 6).

Quanto ao filho John e ao primeiro número do programa, os elogios se dirigem aos seus 12 cavalos e à dança do minueto, quando os animais, obedecendo ao ritmo musical, galantemente avançam as pernas e as flexionam em uma reverência com a cabeça, que alcança o joelho (p. 6).

O número seguinte traz Evelina Price sobre um cavalo alazão, saltando sobre uma fita. Ela é apresentada como uma artista charmosa, que brilha no picadeiro e atrai os homens, mas que não se deixa seduzir e nem se curva diante 
das ofertas de joias e dinheiro que partiam de altas personalidades parisienses. Em meio à apresentação de Evelina, entra em cena Billy Saunders, o palhaço da companhia. O cômico declara seu amor à bela senhorita, que responde com um sorriso indulgente, enquanto pula as fitas sobre o dorso do alazão.

Na sequência, a cortina do palco se abre e o fenômeno da natureza, a criança de 39 meses, toca o seu cravo, o que resulta, na opinião de quem escreveu o texto, em uma lamentável e chata peça. As críticas continuam a ponto de não entender a razão pela qual, na semana anterior, essa criança encantara a corte em Versalhes ${ }^{5}$ e, em tom ácido, pergunta se já alçaram esse "miserável nanico" a um novo Mozart (p. 8).

Os motivos da crítica à performance do pequeno músico não são explicitados. No entanto, parece sintomática a menção à corte: às vésperas da revolução (ela ocorreria três anos depois), o questionamento do gosto e dos costumes de Versalhes era assunto cotidiano nos salões e espaços frequentados pelos burgueses enriquecidos.

Por outro lado, o espetáculo que apresentou até então habilidades humanas incomuns com cavalos, tanto na montaria em pé, como no adestramento e no manejo, fazia uma pausa para um recital de cravo. Não obstante o fato de o intérprete ser uma criança, e, se bom músico (o texto afirma o contrário), adequar-se à categoria das habilidades incomuns, um cravo em meio a um espaço destinado a apresentações grandiosas era desproporcional.

O humor do autor se restabelece parcialmente quando Astley pai adentra o picadeiro com seu cavalo Dick Turpin. O nome do animal fazia referência a Richard Turpin (1705-1739), conhecido ladrão de cavalos inglês, executado em York. Os exercícios apresentados não eram surpreendentes - o autor afirma que viu melhores na Feira de Santo Ovídio ${ }^{6}$. Turpin conseguiu encontrar um lenço feminino de seda no picadeiro, para agradar uma dama da plateia. Ao final, o cavalo saiu da pista equilibrando-se sobre as patas traseiras.

Imediatamente, entra em cena general Jocko, arrastando a cauda de seu casaco na areia e acenando ao público com seu chapéu. O macaco funâmbulo

5 Astley apresentou seu espetáculo à corte em ao menos duas oportunidades: 1774, como já informado, e em 1786, de acordo com o texto, a convite de Maria Antonieta.

6 Tal assertiva vem apoiada, em nota de rodapé, na obra de Campardon (1877),v. 1, p. 201). Porém, na página referida, Campardon cita a feira de Saint-Germain, nos anos de 1749 e 1772. 
executa sua dança na corda com destreza idêntica à de um homem. Depois de atravessar o cabo, repousa na plataforma e, piscando, joga beijos à plateia. Intervalo do espetáculo e o texto manifesta a expectativa da segunda parte e a apresentação do famoso cavalo de caça que Astley almejava vender em Rouen. Interesses comerciais se deixam aflorar. No entanto, a expectativa é interrompida abruptamente com a entrada dos cães adestrados que tumultuam a cena. Um dos cães, de focinho cinza, tem as pernas enrijecidas, provavelmente pela idade avançada, e não consegue acompanhar o frenesi dos demais. Nas palavras do autor, ele aguarda a aposentadoria. Billy Saunders, o domador, finge satisfação pois "os velhos palhaços têm pelos velhos cães decepções amigáveis" (p. 10). Os cães executam proezas conhecidas e vistas em diversos espetáculos, mas sempre propiciam diversão ao público.

Tem início a esperada última parte do espetáculo. A senhorita Polly Saunders se apresenta com Astley filho. No início, "a Inconstância traz a Beleza pelas mãos" (p. 10-11). O texto não apresenta elementos suficientes para a compreensão da natureza técnica e artística da apresentação de ambos ${ }^{7}$. Ao enveredar por comentários que se aproximam, mais uma vez, da crônica social masculina que exala superioridade de classe (no caso, da burguesia), para com artistas, e de gênero, para com as mulheres, o autor afirma que Polly, contrariamente à senhorita Price, "nunca repele as pessoas de distinção" (p. 11). John Astley, por sua vez, é descrito como uma figura amável que agrada ao "belo sexo", opinião baseada nas Mémoires secrets (MÉMOIRES..., 1783, v. 21, p. 70). A Beleza, ao primeiro sinal de deslealdade da Inconstância, dá-lhe com os pés ao ombro e ameaça com um dardo de ouro. Aproximando as afirmações do texto com aquelas expostas por Hillemacher, pode-se inferir que se tratava de uma cena com elementos acrobáticos e de equilíbrio, com temática em torno da moral e da fidelidade conjugal, envolvendo uma dupla de amantes, quando a feminina Beleza domina a masculina Inconstância. Aplausos tomam conta da sala.

7 Em nota de rodapé o texto indica a obra de Hillemacher (1875), que arrola o repertório de toda a dinastia Franconi. Na página 51 encontra-se o registro de "La Beauté maîtrisant I'Innocence", por Philip Astley e Lucy Saunders, em um item denominado "Cenas Representadas no Picadeiro". Tal cena já recebeu o título de "La Beauté maîtrisant victorieusement l'Inconstance", no circo de Astley, e de "l'arrivée de Nicodème dans la Lune, avec son Cheval," levada à cena por Franconi em 1794 (HILLEMACHER, 1875, p. 11). Ver também: Silva (2018, p. 105). 
Em meio à aclamação retumbante, entra em cena, como um velho e gordo camponês da Inglaterra, um dos mais habilidosos acrobatas londrinos, Tom Price. Vestido com casaco azul celeste e usando botas, uma vez sobre o dorso de seus dois cavalos, despoja-se das vestimentas iniciais e prossegue seu número com uma jaqueta vermelha, similar ao uniforme dos soldados britânicos. O título inglês do número de Price é "A Metamorfose Divertida em Dois Cavalos".

Chega, enfim, o momento de maior expectativa do redator e, segundo ele, também dos espectadores: John Astley dança o "Minueto de Devonshire" sobre seus cavalos. O minueto foi composto em honra a Georgina Cavendish (1757-1806), duquesa de Devonshire, e teve sua primeira versão dançada por Adelaide Simonet (1776-1791) e Gaetan Vestris (1729-1808), no Teatro do Rei, em Londres, em 22 de março de 1781 (TUPPEN, 2014). A performance de John se equipara à de Vestris (segundo o texto, autor da coreografia), com um diferencial: ela é executada sobre cavalos correndo na pista. A apresentação é exaltada pelas crônicas da época (MÉMOIRES..., 1784, v. 22, p. 29), que apontam a precisão, a leveza e a nobreza como equivalentes às do dançarino.

Em 1781, John Astley apresentou seu minueto para a corte francesa, quando foi agraciado com uma medalha de ouro cravejada de diamantes.

O espetáculo de Astley está prestes a terminar. Em cena, a pantomima "As lavadeiras inglesas", com máscaras italianas, permeadas de acrobacias diversas, com saltos em janelas, mergulhos em tinas de água, chutes e tapas no rosto e outros golpes diversos. Em meio à agitação da cena, essencialmente acrobática, Colombina atravessa lentamente o espaço, sem se importar com o que acontece ao seu redor. A descrição da cena de 1786 apresenta semelhanças com a entrada circense "As lavadeiras", ainda hoje encenada nos circos brasileiros (BOLOGNESI, 2003, p. 240-241). Nas encenações brasileiras não constam a entrada de uma personagem feminina alheia aos saltos, tapas, chutes etc., tal como a Colombina acima referida.

Fecham-se as cortinas!

\section{Autoria e datas}

Como já apontado, o documento e sua estrutura apresentam um deslocamento temporal de um século. Ele inicia com um alerta quanto aos descontentamento 
em torno do Novo Circo e remete o leitor a cem anos atrás, após uma extensa sequência de pontos, que ocupa uma linha inteira, indicando o intervalo temporal.

Após a linha pontuada, segue o texto alusivo à apresentação de 1786, com descrição de números e artistas, com comentários em tom de crônica social, tal como apresentado anteriormente. Antes de finalizar, o documento apresenta outra linha pontuada e traz de volta o tempo presente, 1887, retomando, assim, a referência ao Novo Circo, inaugurado em 1886.

A escrita de maior fôlego e a que se mostra a mais pertinente para a apreensão do espetáculo de Astley (naquele momento chamado de exercícios) tem como tom principal o olhar de um (ou mais) espectador, que se transforma em cronista. O texto apresenta pistas incertas quanto à autoria. Porém, em meio às incertezas, elas atestam claramente que a base para a descrição e observação dos exercícios apresentados por Astley e seus artistas são as edições de Espion anglais e Mémoires secrets.

Ao final do documento, os senhores “All'eye et All'ear" (em tradução livre, Todos os Olhos e Todos os Ouvidos) saem do recinto quando não há mais nada para ver (p. 15). Em nota de rodapé, a referência a esses senhores é esclarecida: trata-se de Mathieu-François Pidansat de Mairobert (1727-1779), um dos redatores das Mémoires secrets e do Espion anglais. Tal afirmação é confirmada por Barbier. O Dictionnaires des ouvrages anonymes et pseudonymes aponta que "Espion (I')Anglais, ou Correspondance Secrète entre Milord All'eye et Milord All'ear é de autoria de Pidansat de Mairobert" (BARBIER, 1874, v. 2, p. 175). Os dez volumes foram publicados em Londres, entre os anos de 1779-1785. Os quatro primeiros apareceram em 1777-1778, com o título L'observateur anglois, e os outros seis após a morte de Pidansat de Mairobert. Todos os volumes, das duas obras, foram editados em Londres por John Adamson, o mesmo editor de Un soir chez Astley, o documento aqui apresentado.

O Espion anglais foi redigido em forma de cartas e trata dos temas os mais diversos da vida parisiense: literatura, teatro, política, vida cotidiana, guerras etc. Pidansat de Mairobert, cronista e escritor era também "censor real, que cortou as veias no banho, em 17 de março de 1779, porque fora acusado de relações com a imprensa clandestina de Londres" (BARBIER, 1874, v. 2, p. 175). Atenção para afirmação final que aponta a clandestinidade das ações de Pidansat de Mairobert. 
A nota de rodapé da página 15, ao citar o Espion anglais, aponta o anacronismo: como os senhores "All'eye e All'ear" poderiam ter presenciado o espetáculo de Astley em 25 de abril de 1786 se a última edição do Espion ocorreu em 1784? (Equívoco parcial do texto, pois a última edição é de 1785). Ademais, o senhor Pidansat de Mairobert faleceu em 1779.

As Mémoires secrets, relativas aos anos de 1762 a 1784, abordam temas e eventos artísticos e literários de Paris, incluindo peças teatrais, publicações de livros, espetáculos de vaudevilles, críticas e opiniões de homens de letras e artistas, disputas literárias e políticas, especialmente as que se referiam ao embate entre o parlamento e Luis XV, ou seja, assuntos do cotidiano de um modo geral. A escrita obedece a uma ordem cronológica diária.

Os quatro primeiros volumes das Mémoires foram redigidos por Louis Petit de Bachaumont (1690-1771). Com sua morte, Pidansat de Mairobert deu continuidade, seguido, após 1779, ano de seu falecimento, por Mouffle d'Angerville (1728-1795). Ao todo, foram 36 volumes, editados por John Adamson, em Londres, entre os anos de 1777 e 1789. Ou seja, Pidansat de Mairobert está presente na redação das duas obras que dão sustentação factual e opinativa ao texto Un soir chez Astley e John Adamson consta como editor de todas.

Como já ponderado, Pidansat de Mairobert, falecido em 1779, não viu o espetáculo de Astley. O Anfiteatro Inglês foi inaugurado em Paris em 1782 e o Espion anglais foi editado até 1785. Assim, é possível que o autor, escudado no prestígio e nos escritos dos senhores "All'eye e All'ear", personagens espectadores do texto, tenha presenciado o espetáculo circense entre 1782 e 1785.

Uma passagem do texto deixa suspeita quanto à escrita referir-se ao espetáculo de 1786. Na página 5 , logo após o término da descrição do programa do espetáculo, lê-se o seguinte: "Nós iremos sem dúvida para os primeiros lugares. Entramos; a singularidade da decoração do salão já é, como me disse ontem Moufle d'Angerville." O texto, então, remete à primeira nota de rodapé (MÉMOIRES..., 1784, v. 23, p. 280). A edição do volume XXIII das Mémoires é de 1784. De acordo com o texto, o autor ouviu "ontem" de d'Angerville referências à casa de espetáculo. "Ontem" poderia se estender a dois anos, uma vez que o espetáculo é de 1786 e a referência é de 1784? Ou pode-se entender que o "ontem" refere-se a um tempo curtíssimo e, portanto, o espetáculo 
foi visto em 1784. Mas o programa do espetáculo, apresentado no texto, é claro: o espetáculo ocorreu em 25 de abril de 1786.

Com base nos dados e datas acima, pode-se admitir que o narrador do texto se baseou nos escritos de Pidansat de Mairobert, publicados nas Memóires e no Espion (fartamente citados no texto), editados anteriormente à data do espetáculo de Astley. Com base nesses escritos, o desconhecido escritor atesta a veracidade dos feitos e fatos narrados e opiniões emitidas.

Simon Burrows (2006, p. 63) afirma que John Adamson era um falso nome e a maior parte de suas edições referem-se aos escritos de Pidansat de Mairobert. Ademais, o nome Adamson não consta em fontes inglesas relativas a editores e casas editoriais. Sinais da referida clandestinidade se fazem evidentes.

Por sua vez, Steve Ward (2018, p. 10), na investigação documental do Capítulo 2 de sua obra, dedicado à biografia de Philip Astley, afirma que várias informações de Adamson a respeito de Astley são incorretas.

Os dados bibliográficos aqui expostos, bem como o próprio texto Un soir chez Astley, atestam que os escritos de Pidansat de Mairobert, editados por Adamson, são a base da narrativa, que pode ser fruto das "relações clandestinas", sendo que as datas podem ter sido deliberadamente alteradas. $\mathrm{O}$ trabaIho de selecionar trechos dos escritos de Pidansat de Mairobert que abordam o espetáculo de Astley pode perfeitamente ser associado à reprodução, na íntegra, do cartaz apresentado no documento. Trata-se, pois, de uma redação que reúne fragmentos, a partir de um documento: o cartaz do espetáculo. $O$ cartaz e o espetáculo ao qual alude foram, nesse caso, os guias para a seleção de trechos das Mémoires e do Espion que se referem aos números e aos artistas, publicados antes de 1786, data do espetáculo. A edição do documento, vale lembrar, é de 1887.

Se autores e datas foram postos para ludibriar autoridades e leitores (dadas as condições da clandestinidade que levou Pidansart de Mairobert ao suicídio), os artistas arrolados no documento, bem como seus números, são verdadeiros.

\section{A companhia e o espetáculo}

Pelos dados do documento, a companhia dirigida por Philip Astley, na temporada em Paris, em 1786, era composta por três núcleos familiares: os Astley, 
os Prices e os Saunders. Os primeiros, proprietários do Anfiteatro, exibiam as suas especialidades, ou seja, as atrações com cavalos. Billy Saunders, o pai, era o cômico da companhia; sua filha participava do número com Astley filho, "A Beleza dominando a Inconstância.'A senhorita Price também trabalhava com cavalos, no salto sobre a fita, e Tom Price, seu pai, era um habilidoso acrobata.

A organização de espetáculos em torno de núcleos familiares possibilita o aproveitamento de todos que estejam com idade e condições artísticas de trabalho. Tal estrutura era conhecida e praticada desde os tempos do mambembear de saltimbancos, de bufões, de comediantes, de acrobatas, de domadores, de artistas do palco etc. Por ocasião das feiras, os diversos artistas e suas famílias se encontravam e faziam acordos para, por um tempo determinado, caminharem juntos com um espetáculo ampliado. No Teatro de Feira e posteriormente nos teatros dos bulevares, tal prática teve continuidade. $\mathrm{O}$ circo também se apropriou dessa prática conhecida.

Quanto ao espetáculo apresentado por Astley, em 1786, os "exercícios" foram concebidos como uma montagem de atrações. Tal procedimento fora experimentado à exaustão e condensado pelos diversos espaços teatrais que compunham o denominado Teatro de Feiras, em seus variados gêneros e subgêneros, que vieram a se consolidar na ópera-cômica.

Em relação às atrações apresentadas nas feiras, permeadas de cenas e enredos teatrais, o diferencial de Astley foi justamente a inserção dos exercícios com cavalos, em várias modalidades, em meio a acrobacias, cenas cômicas, animais amestrados (selvagens ou não) e a pantomima final. Os exercícios com cavalos conquistaram o público burguês parisiense, que passou a ter acesso, por vias comerciais e espetaculares, aos "símbolos e segredos" cultuados e guardados pela aristocracia.

O programa de 1786 era composto de dez números dos quais ao menos cinco traziam cavalos à pista. Um macaco equilibrista e os cães adestrados completavam o rol de números com a presença de animais. Restavam, portanto, três números que não traziam animais: a criança-prodígio e seu cravo, a abertura da segunda parte com "A Beleza dominando a Inconstância", e a pantomima "As lavadeiras inglesas". Tratava-se, pois, de um espetáculo com predomínio de animais, bastante diverso daqueles do tempo da edição da obra (1887), cuja referência é dada pelo Novo Circo e sua arena aquática. 
A composição do espetáculo de Astley se apoia na conhecida polaridade dos espetáculos de atrações, qual seja a oscilação entre o sublime e o grotesco, permeada sempre pelo sentido do inusitado, do incomum, do não natural e, fundamentalmente, do risco. A sublimidade está presente nos artistas e números com cavalos, nas várias modalidades, na criança e seu cravo, em Tom Price na acrobacia sobre o cavalo e no número da senhorita Saunders e Astley filho, "A Beleza dominando a Inconstância". O grotesco está presente nas cenas do palhaço Billy Saunders, no general Jocko, nos cães amestrados e na pantomima final.

O espetáculo de Astley, de 1786, apresenta as bases sobre as quais se fundariam os futuros espetáculos circenses. Evidentemente, não é ele o criador de tais bases e nem é possível saber ao certo quem o foi. Como aludido, elas foram experimentadas e lapidadas por um longo período histórico, chegando ao Teatro de Feira, quando receberam o devido coroamento e a certeza de que esse modo de conceber espetáculo atende à demanda e às expectativas de um vasto público. Essa maneira de construção espetacular possibilita o alinhamento de atrações artísticas as mais variadas, fazendo oscilar o sublime e o grotesco, o alto e o baixo, o lírico com o jocoso, o nobre e o plebeu etc., em uma infinidade de combinações. O elemento essencial a conduzir tal montagem é a música, que assegura o ritmo dos números, variando entre lentos e rápidos. Daí a imprescindível presença da orquestra a ocupar um lugar de destaque no espaço arquitetônico, em conjugação entre palco e picadeiro. Mas a montagem de atrações também pode construir enredos e narrativas e, com isso, acolher cenas teatrais permeadas (ou não) de movimentos e interpretações acrobáticas, a exemplo da pantomima apresentada por Astley.

A história do espetáculo circense demonstra que esse procedimento ganhou investidas maiores, a exemplo dos hipodramas e dramas históricos apresentados no recinto circense. O Novo Circo não fugia à regra. Nele, no entanto, o cavalo não tinha a primazia do espetáculo. Mas isso é assunto para outro momento!

\section{Referências bibliográficas}

BARBIER, A. A. Dictionnaire des Ouvrages Anonymes. 3. ed. Paris: Paul Daffis, 1874. v. 2. Disponível em: https://bit.ly/2XLfDOp. Acesso em: 14 jun. 2019. 
BEAULIEU, H. Les Théâtres du Boulevard du Crime: de Nicolet à Déjazet (1752-1862). Paris: H. Daragon, 1905.

BOLOGNESI, M. F. Palhaços. São Paulo: Editora Unesp, 2003.

BURROWS, S. Blackmail, scandal and revolution: London's French libellistes, 1758-1792. Manchester: Manchester University Press, 2006.

CAMPARDON, E. Les spetacles de la foire. Paris: Berger-Levrault, 1877. 2 v.

HILLEMACHER, F. Le Cirque Franconi: détails historiques sur cet établissement hippique et sur ses principaux écuyers. Lyon: Alf. Louis Perrin \& Marinet, 1875. Disponível em: https://bit.ly/2KQTCtS. . Acesso em: 14 jun. 2019.

LES ANCIENS cirques: un soir chez Astley (25 Avril 1786). Londres: John Adamson, 1887. Disponível em: https://bit.ly/2KQS7Mg. Acesso em: 14 jun. 2019.

MÉMOIRES secrets pour servir à l'histoire de la republique des lettres em France ou Journal d'un observateur. Londres: John Adamson, 1777-1789. 36 v. Disponível em https://gallica.bnf.fr. Acesso em: 14 jun. 2019.

SILVA, R. C. da. Dionísio pelos trilhos do trem: circo e teatro no sertão do Brasil. Curitiba: CRV, 2018.

TUPPEN, S. Devonshire minuets. Music Blog, London, 14 fev. 2014. Disponível em: https://bit.ly/2WK6eue. Acesso em: 5 dez. 2018

WARD, S. Father of the Modern Circus 'Billy Buttons': the life and times of Philip Astley. Barnsley: Pen \& Sword, 2018.

Recebido em 21/02/2019

Aprovado em 12/06/2019

Publicado em 30/08/2019 